\section{Graham Johnson}

An illustrator drops the barriers between work and play with software to model and explore cells.

Graham Johnson wants his tools to help researchers make observations inside of cells, traveling much as the explorer Jacques Cousteau did in ocean depths. This is "submarining through interacting molecules while

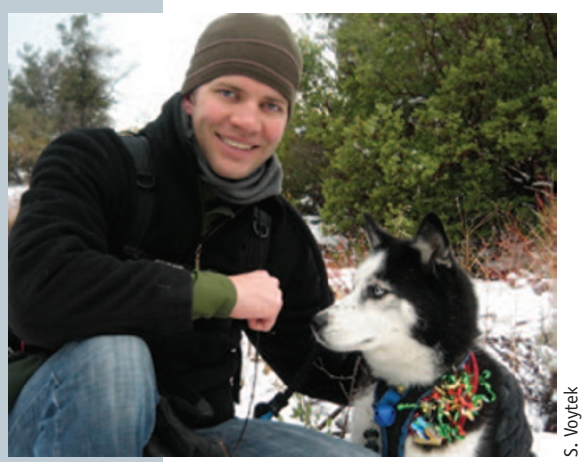

Graham Johnson with Flower searching, exploring, observing, experimenting and learning," says Johnson, a faculty fellow at California Institute of Quantitative Biosciences (QB3) at the University of California in San Francisco.

He has developed the open-source software tools autoPACK and cellPACK, with

which scientists and illustrators can model, visualize and simulate three-dimensional spatial data. The software offers ways to quickly and repeatedly construct and share spatial models with others. For example, researchers can tweak a facet of a model that looks incorrect or draw on new data to update a given model.

Modeling, says Johnson, is best not performed with a pour-and-stir approach, in which molecules and organelles fill a virtual container and are stirred until uniformly random. Instead, packing algorithms must recapitulate all the results that natural forces produce throughout a given volume, and the objects must be placed according to known geometries and probabilities.

In its current version, the software focuses on modeling systems between 10 and 1,000 nanometers in size. As an animator and illustrator, Johnson has worked extensively on one-off manual interpretations in this mesoscale, which is where important cellular activity occurs. Molecular interactions, such as protein phosphorylation, happen on the lower end of this scale, and higher molecular assemblies, such as organelles, are at the upper end. cellPACK is an automated way to model structures, unite data and experiment in the mesoscale and, eventually, beyond that scale, he says.

Researchers can experiment with the software's settings to see or even try to predict larger-scale properties. "We look forward to having more biologists and programmers contribute to this project," says Johnson. The software can also help assemble data and reconcile competing theories. "By directly visualizing mental models, researchers can easily point to and discuss their quibbles with competing models rather than trying to visualize their theories or critiques with only hand gestures and napkin sketches," he says.

cellPACK is the largest programming project Johnson has ever undertaken, and he has been ruminating on it for over a decade. The impact of such models hit home for him when he and others used 3D printing to hold in their hands a model of a cubic micrometer of blood plasma or a full HIV particle.

"Graham was an artist before becoming a scientist, and it shows in how he works," says Art Olson, coauthor on the current paper. Olson directs the Molecular Graphics Lab at The Scripps Research Institute and was Johnson's $\mathrm{PhD}$ advisor. He says Johnson is a fountain of ideas and a perfectionist who always looks at projects as pictures that tell a story. "I never stopped marveling at his creative and aesthetic sensibilities," says Olson.

Johnson grew up near Baltimore. As a graduate student in medical illustration at Johns Hopkins University, he studied anatomy alongside medical students, drawing what he saw. Autopsies and dissection were often shocking, says Johnson, but mixed in with the efficient brutality of the autopsy procedure was "the wonder and beauty of our complex anatomy that looks so colorful and alive compared to our gray-beige cadavers."

Johnson began showing a knack for observational drawing in fourth grade. He headed, murkily, toward a biology degree but ramped up his enthusiasm by designing his own major, which led him to
“I realized how exciting the molecular biology of cells could be..." medical illustration.

At the Salk Institute, he illustrated the textbook Cell Biology, learning the subject one figure at a time with one of the authors, Thomas Pollard. "I realized how exciting the molecular biology of cells could be, especially for an illustrator-there were so many new things discovered every day," says Johnson. "Many components had never been visualized or effectively explained to the many new audiences eager to learn about them."

To enjoy the mountains, he moved to Colorado and did freelance molecular and cellular biology illustration and animation. Johnson kept dreaming about modeling cells dynamically. He went back to school and completed his $\mathrm{PhD}$ in biophysics in Olson's lab. Then, in 2012, he became a QB3 faculty fellow.

Johnson calls Olson a smart, caring, personal and scientific mentor whose lab was one of a very few that were able to nurture a project like cellPACK. "I aim to follow in his footsteps," says Johnson, and run a lab that links biology and visualization.

\section{Vivien Marx}

Johnson, G.T. et al. cellPACK: a virtual mesoscope to model and visualize structural systems biology. Nat. Methods 12, 85-91 (2015). 